\title{
Association between social capital and sleep duration among rural older adults in China
}

\author{
Le Yang $^{1 *}$, Hongman Wang ${ }^{2}$ and Jingmin Cheng ${ }^{1}$
}

\begin{abstract}
Objective: Sleep disturbances are great challenges to older adults' health promotion. The study tested gender differences in the association between different dimensions of social capital and self-reported sleep duration of Chinese rural older adults.

Design: The data of rural older adults were extracted from a national cross-sectional survey of the Chinese Longitudinal Healthy Longevity Survey (CLHLS) and analyzed in this study.

Setting: CLHLS covered 23 provinces in China.

Participants: The 6552 rural respondents aged $\geq 65$ years old were involved.

Main outcome measures: Generalized trust, informal social participation, formal social participation and social support were used to assess social capital. Self-reported sleep duration was measured as health outcome.

Results: Low level of generalized trust had harmful effect on insufficient sleep (AOR 1.110, 95\% Cl 1.018-1.324), and having no formal or informal social participation was significantly positively associated with long sleep (AOR formal $\left.1.424,95 \% \mathrm{Cl} 1.007-2.013 ; \mathrm{AOR}_{\text {informal }} 1.241,95 \% \mathrm{Cl} 1.016-1.516\right)$. Rural older female adults with no emotional social support had higher odds of insufficient sleep (AOR 1.502, 95\% Cl 1.258-1.978). Meanwhile, both informal and formal social participation showed inverse association with long sleep for females.

Conclusions: This study found the relationship between social capital, sleep duration and the gender differences in Chinese rural older adults. More targeted sleep disturbance interventions could be taken in social capital of rural older adults, and gender differences should be considered when making social capital-embedded health promotion policies and interventions.
\end{abstract}

Keywords: Social capital, Sleep duration, Rural older adults, China

What is already known on this subject: Sleep has gradually become a focus of old adults' health research for its impact on health. Numerous studies have suggested that social capital may be associated with sleep.

What does this study add: This study aimed to address the research questions that if there were connection between

\footnotetext{
${ }^{*}$ Correspondence: yangle05@hotmail.com

${ }^{1}$ School of Management, Shanxi Medical University, 56 Xinjian South

Road, Taiyuan, Shanxi Province, China

Full list of author information is available at the end of the article
}

social capital and sleep duration and its gender differences in Chinese rural older adults.

\section{Introduction}

Sleep has gradually become a focus of old adults' health research for its impact on health. Sleep disturbances are great challenges for the older adults' health promotion and sleep disorders are common in older adults for their decreasing ability to maintain sleep as the age increases [1]. With regards to sleep duration, there is a U-shaped association whereby short sleep is associated with health risks, as is long sleep, such as depression, obesity, 
cognitive impairment, and cardiovascular disease [2-5]. While sleep problems are always discussed and explained by age, there are many other factors accompanying aging, and sleep problems in older adults could be explained in multifactorial path. Many factors in the aging process, including physical and psychological conditions, changes in socio-economic environment and lifestyle, may cause sleep problems in older adults [6].

Among the social factors affecting sleep, social capital has been confirmed to be related to the sleep disturbances. Social capital refers to the association between individuals or groups, i.e. social networks, reciprocity, norms, trust and participation, and people could obtain resources and help from their social capital. The current approaches in social capital are mainly divided into two dimensions, social cohesion, and social network. Social cohesion places more emphasis on social capital at the macro-level, such as social trust, reciprocity and norms, while the social network is mainly concerned with micro-level social capital, such as the density and scope of an individual's social network $[7,8]$. There are many different perspectives in social capital measures, including cognitive (individuals' perceptions, values, beliefs, and attitudes) and structural (externally observable social interactions), bonding (relations between people of groups of similar social identity), bridging (relations between people of groups of different social identity) and linking (formal relations to people of power and authority) [9-11]. Robbins (2019) found that short and long sleep duration were inversely related to measures of social capital, such as group memberships and a sense of neighborhood belonging, in adults in the Philadelphia area [12]. Another study showed poor neighborhood social capital was associated with insufficient sleep duration among rural Japanese adults [13]. In China, the association between social capital and sleep has also been studied, and previous researches presented that higher level of social capital is associated with higher sleep quality $[14,15]$. However, few studies explored the association between social capital and sleep duration in China.

Due to the differences in age, gender, nationality, socioeconomic status, living environment, people have access to and rely on different sources and forms of social capital, thereby forming different means by which social capital affects health and different health outcomes. Gender difference, an important way to explain gender differences in health, has to rural social capital and sleep. Sleep disturbances increase with age in both males and females. While men and women sleep differently, women always typically report poorer quality and more disrupted sleep across various stages of life [16]. In addition, gender differences in forms of social capital and source of social connection would help to explain the gender difference in sleep disturbances [17-19]. Basset and Moore (2014) found the association among restless sleep, social capital, and neighborhood environmental factors differed in genders in Montreal adults [20]. In China, older adults with high-frequency of social engagement may have better sleep quality, but the positive relation between different types of social engagement and sleep quality was different between male and female [21]. Given the results of studies on gender differences in the association between social capital and health outcomes were inconsistent, the gender differences in the association between sleep duration and social capital remains to be examined.

Many studies have confirmed the differences in social capital between rural and urban elderly residents [22, 23]. China is a typical guanxi-based society, and guanxi in China refers to the personal connections or the special bonds in interpersonal networks, which are enduring, reciprocal, and sentimentally based instrumental relations [24-26]. Chinese tend to seek for social support through the guanxi and maintain the interpersonal network in their social life [27]. The traditional "guanxi" culture takes root more deeply in the rural area, and evidence shows "guanxi" and social capital have similar connotations and effects [28]. Previous studies show that bonding social capital comprising a connection between community members is often stronger among rural older adults, resulting in higher level of interpersonal trust, reciprocity and community cohesion [29, 30]. With the rapid urbanization and changes in family structure, older adults in rural areas need to face more obstacles to get care and support from family members (i.e., sons and daughters) who have increasingly migrated to urban areas for education and work opportunities [31, 32]. Some of them relocate to the town or city with their family members, which would affect the social capital of rural older adults, thereby affecting their health. Rural older adults predominate the old population in China, while to our knowledge, there are few studies focusing on association between social capital and rural older adults' sleep duration. Given the concerning relationship between sleep duration and social capital, questions still remain unanswered regarding the underlying pathways between sleep duration and social capital among rural older adults in China.

Accordingly, in the present study the association between social capital and self-reported sleep duration in Chinese rural older adults were tested using a national sample of China. This study aimed to address the research questions that if there were connection between social capital and sleep duration and its gender differences in Chinese rural older adults. 


\section{Methods}

\section{Study design and population}

Chinese Longitudinal Healthy Longevity Survey (CLHLS) covered 23 provinces and is the largest set of survey data of the old adults in China [33]. CLHLS conducted population surveys with 15,874 individuals in 20172018 (wave 8), including rural and urban areas, using a domiciliary face-to-face questionnaire, in the countries' native language. In this study, those whose Hukou status (household registration) were rural and aged $\geq 65$ were recognized as rural older adults. This study excluded respondents who were urban residents $(n=4477)$, under 65 years old $(n=74)$, lacked sleep duration information $(n=579)$, or provided implausible sleep duration of $<2$ or $>16 \mathrm{~h}$ per day [34] $(n=81)$. The respondents who did not answer all the questions were regarded as unreliable and were excluded from the analysis, among them, 991 individuals missed social capital related information, 2877 individuals did not have complete sociodemographic data, and 243 individuals did not provide health related information. A final total of 6552 respondents were analyzed.

\section{Measures \\ Social capital}

In health research on social capital and health outcomes, due to the different choices of social capital measures, the research results are also various. The results of research reports focusing on the relationship between collective social capital and health are not that clear, while social capital measures in individual-level is mostly found to be closely related to positive health outcomes [35]. This research was mainly concerned with the impact of individual-level social capital on sleep disturbances of old adults. This study combined elements of different approaches to capture individual-level social capital, such as generalized trust, social participation, and social support, which were shown as important social capital measures associated with health changes and healthcare utilization [36-38]. Social capital was captured using five variables measured: generalized trust (representing cognitive social capital); informal social participation and formal social participation [39] (representing structural social capital); emotional and instrumental social support (representing output).

1. Question about generalized trust: Do you feel that people around you are trustworthy? The variable response was classified into $1=$ trustworthy, $0=$ untrustworthy.

2. Question about social participation: (1) informal social participation: Do you visit and interact with friends regularly? The variable response was divided into $1=$ yes, $0=$ no; (2) formal social participation: Do you take part in social activities (organized) regularly? The variable response was divided into $1=$ yes, $0=$ no.

3. Question about social support: (1) Is there anyone that you could talk to when you need to tell something of your thoughts? (emotional social support); (2) Is there anyone you could ask for help when you have problems/difficulties? (instrumental social support). The variable response was grouped into $1=$ yes, $0=$ no.

\section{Sleep variables}

The average sleep duration per day of a participant was obtained using the question "How many hours do you sleep normally every day including napping?", with respondents giving an integer number. Given the review of current related studies [40,41], this study defined the sleep duration of 7-9h per day as the normal sleep duration for old adults, $<7 \mathrm{~h}$ per day as insufficient sleep, and $>$ $9 \mathrm{~h}$ per day as long sleep.

\section{Covariates}

This study selected the following as potential confounders according to the previous studies [12, 13, 42]. The first group of potential confounders were demographic and socioeconomic characteristics, including age, gender, current residential area, education (assessed as years of schooling), pension status (with pension vs. without pension), living alone (yes vs. no), marital status, and annual household income. Current residential area was classified as city, town, and rural area. Years of schooling was divided into 0 (uneducated), 1-6 years (primary school), 7-12 years (middle school and high school), and $\geq 13$ years (college or above). Marital status was grouped as "married and living with spouse, separate, divorced, widowed, never married". Household annual income was categorized as follows: low ( $\leq 10,000$ yuan), medium $(10,000-36,000$ yuan), high $(>36,000$ yuan). The second group consisted of variable of health behaviors, including current smoking (yes vs. no), current drinking (yes vs. no), and physical activity (yes vs. no). Lastly, covariates of variables of health condition were examined, such as sleep quality, body mass index (BMI), depressive symptoms, activities of daily living (ADL), cognitive function, noncommunicable disease (NCD), and comorbidity. The measure of self-reported sleep quality was dichotomized into very good/good versus other (fair/bad/very bad), and was treated as a binary outcome. The 10-item Center for Epidemiologic Studies Short Depression Scale 
(CES-D) was adopted to measure the depression symptom, scoring from 0 to 30 [43, 44]. ADL was based on whether the respondent could be independent in feeding, bathing, dressing, toilet hygiene, continence and indoor transferring, each item was scored from 1 to 3 (1 score representing complete independence; 2 scores representing partially dependence; 3 scores representing complete dependence), and lower scores indicating better functional independence. Cognitive function was measured using the Chinese version of Mini-Mental State Examination (MMSE), with a score ranging from 0 to 30 [45].

\section{Statistical analysis}

This study was conducted to explore the association of social capital and self-reported sleep duration as well as its gender difference in the rural older adults. The continuous variables were described using mean and standard deviation (SD), and the categorical variables were presented by number and proportion (\%). Given that the sampling weight variable in the CLHLS dataset was estimated based on the estimated numbers of older adults by age, sex, and rural/urban residence and there were no other important compositional variables, this study did not apply sample weights in the regression analyses, but the sampling weights were applied in the descriptive analysis and comparative analysis. Several studies have suggested that including variables related to sample selection in the regression produces unbiased coefficients without weights [46] and weighted regression results are likely to enlarge the standard errors [47].

To clarify the effects of social capital on sleep duration, a stepwise approach was used to adjust for different sets of confounding variables. Preliminary logistic regression model (model 1) was generated by applying merely the social capital variables to assess the association of social capital and sleep duration. In model 2, the study further adjusted for demographic and socioeconomic characteristics, in model 3, the study adjusted for demographic and socioeconomic characteristics, and health behaviors, and in model 4, the study adjusted for all confounders. Participants with sleep duration of $7-9 \mathrm{~h}$ were set as the reference groups. Results were presented as ORs, 95\% CI and corresponding $\mathrm{P}$ values. To examine gender differences in the association of social capital and sleep duration, we performed stratified analyses by gender group, adjusting for all confounders.

All statistical analyses were performed by SPSS ver. 24.0 (IBM, Armonk, NY, USA). The significance level was at two-tailed $P$-value $<0.05$.

\section{Results}

The demographic and socioeconomic characteristics of respondents were presented in Table 1 , most rural older adults (61.25\%) lived in rural areas currently, but some lived in other areas (35.98\% in town and $2.77 \%$ in city). There were $52.4 \%$ of participants reporting insufficient sleep (sleep duration $<7$ h every day), and a small number of older adults (18.3\%) experienced long sleep.

Approximately $44.3 \%$ of the respondents were male and $55.7 \%$ were female. The proportions of female, without pension, uneducated, and widowed were relatively higher among those who reported insufficient sleep and long sleep $(P<0.01)$. The similar proportions of the participants having NCD were observed among short and normal sleepers and lower proportion among long sleepers $(P<0.01)$. The mean age was relatively older among those who had long sleep $(P<0.001)$. A higher percentage of older population with low household annual income reported insufficient sleep $(P<0.001)$. Meanwhile, older adults of normal sleep and long sleep showed lower percentage of non-smoking and non-drinking, and the proportion of those who did no physical exercise was higher among long sleepers. The mean score of ADL was relatively higher among those who suffered insufficient sleep and long sleep $(P<0.001)$, and the mean score of depression symptom was higher among the long-sleep older adults. The rural older adults in China had higher social trust, more informal social activity involved, higher social support, but less formal social participation.

Multinominal logistic regressions on grouped sleep duration as a dependent variable were carried out (Table 2). Across all models, a significant association was found between generalized trust and insufficient sleep after controlling all potential confounders. Generalized trust had protective effect on insufficient sleep, older adults feeling people around them untrustworthy showed greater odds of short sleep in Model 1[Odds Ratio (OR) 1.237, 95\% Confidence Interval (95\% CI) 1.088-1.407], and the harmful effects were shrunk after controlling all the confounders in Model 4 [Adjusted Odds Ratio (AOR) 1.110, 95\% CI 1.018-1.324]. Meanwhile, formal social participation was significantly inversely associated with long sleep. The older adults who did not participate in organized social activities had greater odds of long sleep in Model 1 (OR 1.678, 95\% CI 1.275-2.208). After adjusting confounders (gender, age, education, marital status, current residential area, pension status, living alone, household annual income, smoking, alcohol drinking, physical activity, sleep quality, depression, BMI, ADL, cognition function, NCD and commodity), the harmful impacts were attenuated in Model 4 (AOR 1.424, 95\% CI 
Table 1 Characteristics of the old adults by sleep duration

\begin{tabular}{|c|c|c|c|c|}
\hline & $<7 \mathrm{~h}$ & $7-9 h$ & $>9 \mathrm{~h}$ & $p$ value \\
\hline Gender, N (\%) & & & & $<0.001$ \\
\hline Male & $1647(40.1 \%)$ & $1150(50.0 \%)$ & $680(47.4 \%)$ & \\
\hline Female & $2461(59.9 \%)$ & $1151(50.0 \%)$ & $756(52.6 \%)$ & \\
\hline Age, mean (SD) & $81.77(11.24)$ & $81.75(11.28)$ & $87.19(11.32)$ & $<0.001$ \\
\hline Household annual income, N (\%) & & & & $<0.001$ \\
\hline$\leq 10000$ & $1871(45.5 \%)$ & $895(38.9 \%)$ & $571(39.8 \%)$ & \\
\hline $10000-36000$ & $997(24.3 \%)$ & $618(26.9 \%)$ & $359(25.0 \%)$ & \\
\hline$>36000$ & $1240(30.2 \%)$ & $788(34.2 \%)$ & $506(35.2 \%)$ & \\
\hline Having pension & & & & $<0.001$ \\
\hline Yes & $334(8.1 \%)$ & $266(11.6 \%)$ & $120(8.4 \%)$ & \\
\hline No & $3774(91.9 \%)$ & $2035(88.4 \%)$ & $1317(91.6 \%)$ & \\
\hline Education & & & & $<0.001$ \\
\hline Uneducated & 2132(51.9\%) & $1063(46.2 \%)$ & $823(57.3 \%)$ & \\
\hline Primary school & $1577(38.4 \%)$ & $887(38.5 \%)$ & $504(35.1 \%)$ & \\
\hline Middle school and high school & $375(9.1 \%)$ & $321(13.9 \%)$ & 102(7.1\%) & \\
\hline College or above & $24(0.6 \%)$ & $31(1.3 \%)$ & $8(0.5 \%)$ & \\
\hline Live alone & & & & $<0.05$ \\
\hline Yes & $121(2.9 \%)$ & $45(2.0 \%)$ & $47(3.3 \%)$ & \\
\hline No & $3987(97.1 \%)$ & $2256(98.0 \%)$ & 1389(96.7\%) & \\
\hline Marital status, N (\%) & & & & $<0.001$ \\
\hline Married and living with spouse & 1923(46.8\%) & $1136(49.4 \%)$ & $496(34.5 \%)$ & \\
\hline Separated & $76(1.9 \%)$ & $42(18 \%)$ & $12(0.8 \%)$ & \\
\hline Divorced & $10(0.2 \%)$ & $0(0.0 \%)$ & $8(0.6 \%)$ & \\
\hline Widowed & $2071(50.4 \%)$ & $1100(47.8 \%)$ & $903(62.9 \%)$ & \\
\hline Never married & $27(0.7 \%)$ & $23(1.0 \%)$ & $17(1.2 \%)$ & \\
\hline Current residential area, N (\%) & & & & 0.332 \\
\hline City & $123(3.0 \%)$ & $64(2.8 \%)$ & $30(2.1 \%)$ & \\
\hline Town & $1497(36.4 \%)$ & $808(35.1 \%)$ & $517(36.0 \%)$ & \\
\hline Rural & $2487(60.6 \%)$ & $1429(62.1 \%)$ & $889(61.9 \%)$ & \\
\hline Smoking, N (\%) & & & & $<0.01$ \\
\hline Yes & $687(16.7 \%)$ & 459(19.9\%) & $263(18.3 \%)$ & \\
\hline No & $3421(83.3 \%)$ & $1842(80.1 \%)$ & $1174(81.7 \%)$ & \\
\hline Alcohol drinking, N (\%) & & & & $<0.001$ \\
\hline Yes & $586(14.3 \%)$ & $405(17.6 \%)$ & $261(18.2 \%)$ & \\
\hline No & $3522(85.7 \%)$ & $1896(82.4 \%)$ & $1175(81.8 \%)$ & \\
\hline Physical activity, N (\%) & & & & $<0.01$ \\
\hline Yes & $1173(28.6 \%)$ & $738(32.1 \%)$ & $383(26.7 \%)$ & \\
\hline No & 2935(71.4\%) & $1563(67.9 \%)$ & 1054(73.3\%) & \\
\hline Having NCD, N (\%) & & & & $<0.01$ \\
\hline Yes & $2804(68.2 \%)$ & $1563(67.9 \%)$ & $905(63.0 \%)$ & \\
\hline No & 1305(31.8\%) & $738(32.1 \%)$ & $532(37.0 \%)$ & \\
\hline Comorbidity, N (\%) & & & & $<0.01$ \\
\hline Yes & $1500(36.5 \%)$ & $837(36.4 \%)$ & $460(32.0 \%)$ & \\
\hline No & $2608(63.5 \%)$ & $1464(63.6 \%)$ & $977(68.0 \%)$ & \\
\hline Sleep quality, N (\%) & & & & $<0.001$ \\
\hline Good/very good & $1260(30.7 \%)$ & $1649(71.7 \%)$ & $1141(79.5 \%)$ & \\
\hline Other & $2848(69.3 \%)$ & $652(28.3 \%)$ & 295(20.5\%) & \\
\hline ADL score, mean (SD) & $6.66(1.99)$ & $6.51(1.72)$ & $6.71(1.75)$ & $<0.01$ \\
\hline MMSE score, mean (SD) & $24.86(6.19)$ & $25.16(6.04)$ & $23.61(6.72)$ & $<0.001$ \\
\hline
\end{tabular}


Table 1 (continued)

\begin{tabular}{|c|c|c|c|c|}
\hline & $<7 \mathrm{~h}$ & $7-9 h$ & $>9 h$ & $p$ value \\
\hline Depression score, mean (SD) & $6.84(3.15)$ & $7.31(2.79)$ & $7.43(3.08)$ & $<0.001$ \\
\hline BMI, mean (SD) & 25.40 & 27.88 & 29.57 & $<0.01$ \\
\hline Generalized trust, N (\%) & & & & $<0.001$ \\
\hline Trustworthy & 2919(71.1\%) & $1750(76.0 \%)$ & 1065(74.1\%) & \\
\hline Untrustworthy & $1189(28.9 \%)$ & $552(24.0 \%)$ & $372(25.9 \%)$ & \\
\hline Social participation (informal), N (\%) & & & & $<0.001$ \\
\hline Yes & $2706(65.9 \%)$ & $1514(65.8 \%)$ & $782(54.4 \%)$ & \\
\hline No & $1402(34.1 \%)$ & $787(34.2 \%)$ & $655(45.6 \%)$ & \\
\hline Social participation (formal), N (\%) & & & & $<0.001$ \\
\hline Yes & $461(11.2 \%)$ & $267(11.6 \%)$ & $100(7.0 \%)$ & \\
\hline No & $3647(88.8 \%)$ & 2034(88.4\%) & 1336(93.0\%) & \\
\hline Social support (emotional), N (\%) & & & & 0.169 \\
\hline Yes & $4015(97.7 \%)$ & $2234(97.0 \%)$ & 1406(97.8\%) & \\
\hline No & $93(2.3 \%)$ & $68(3.0 \%)$ & $31(2.2 \%)$ & \\
\hline Social support (instrumental), N (\%) & & & & 0.010 \\
\hline Yes & $4048(98.5 \%)$ & 2280(99.1\%) & $1429(99.4 \%)$ & \\
\hline No & $60(1.5 \%)$ & $21(0.9 \%)$ & $8(0.6 \%)$ & \\
\hline Cases, N (\%) & $4108(52.4 \%)$ & $2301(29.3 \%)$ & 1437(18.3\%) & \\
\hline
\end{tabular}

$P$ values are calculated with analysis of Chi-squared test for categorical variables and variance (ANOVA) for continuous variables

1.007-2.013). The older adults who did not have informal social participation had greater odds of long sleep in Model 1 (OR 1.604, 95\% CI 1.387-1.855), but the association was attenuated when variables of health condition (Model 4) were added.

We further examined whether the association between social capital and sleep duration differed according to gender. As shown in Table 3, female older adults who had no emotional social support had higher odds of insufficient sleep (AOR 1.502, 95\% CI 1.258-1.978), but males did not. At the same time, both informal and formal social participation showed inverse association with long sleep for females (i.e. people without social participation showed greater odds of long sleep).

\section{Discussion}

Using data from CLHLS-across-sectional survey, this study provided evidence for an association between social capital and sleep duration and its gender differences among Chinese rural older adults. This study found that generalized trust had protective effect on short sleep, as well as social participation (informal and formal) on long sleep, after controlling all potential confounders, but the association was modest. More female rural older adults reported short sleep or long sleep than males did. Having no emotional social support was associated with higher odds of short sleep and having no social participation (informal and formal) was associated with higher odds of long sleep among females.
The study found that generalized trust was associate with insufficient sleep. Old adults who did not trust people around them showed greater odds of insufficient sleep. With low-level of trust, rural old adults are less likely to get sense of safety and health information from interaction with other people and collective action, therefore they are physically and mentally vulnerable and have a high possibility of social isolation. Some studies have claimed that sleep is more a psychological behavior and the stress-buffering effect of a trustful and safe social environment on falling asleep $[48,49]$. When people feel stressed, they usually feel physical tension and mental stress, and are more sensitive to the sleeping environment, or they focus too much on sleep, which may influence their sleep quality and shorten their sleep duration [50]. Higher level of trust is conducive to stress relief, information (health related) contagion and health behavior modification, which could improve sleep quality by reducing anxiety and stress [14].

Social support, as one of the important social factors affecting physical and psychological health of older adults $[51,52]$, refers to a person's perception of the availability of help or support from others through their social network [53]. Many evidences have showed a robust association between social support and favorable sleep outcomes $[54,55]$. This study found that emotional social support played an important role in rural older women's insufficient sleep. Women always show greater responses to sleep loss in terms of mood deficits [56, 57]. 
Table 2 Logistic regression analysis of the association between social capital and sleep duration

\begin{tabular}{|c|c|c|c|c|c|}
\hline & & Model 1 (Crude OR) & Model $2^{\mathrm{a}}$ & Model $3^{b}$ & Model $4^{c}$ \\
\hline \multirow[t]{10}{*}{$<7 \mathrm{~h}$} & Generalized trust & & & & \\
\hline & Untrustworthy & $1.237^{* *}(1.088-1.407)$ & $1.227^{* *}(1.078-1.397)$ & $1.226^{* *}(1.077-1.396)$ & $1.110^{*}(1.018-1.324)$ \\
\hline & Informal social participation & & & & \\
\hline & No & $0.986(0.875-1.112)$ & $0.978(0.862-1.109)$ & $0.967(0.851-1.098)$ & $0.930(0.783-1.106)$ \\
\hline & Formal social participation & & & & \\
\hline & No & $1.021(0.849-1.228)$ & $0.946(0.783-1.143)$ & $0.928(0.768-1.123)$ & $1.017(0.792-1.305)$ \\
\hline & Social support (emotional) & & & & \\
\hline & No & $0.730(0.503-1.059)$ & $0.677(0.465-0.986)$ & $0.682(0.468-0.994)$ & $0.590(0.350-0.994)$ \\
\hline & Social support (instrumental) & & & & \\
\hline & No & $1.395(0.756-2.573)$ & $1.418(0.764-2.629)$ & $1.432(0.771-2.657)$ & $2.240(0.868-7.110)$ \\
\hline \multirow[t]{10}{*}{$>9 h$} & Generalized trust & & & & \\
\hline & Untrustworthy & $1.046(0.889-1.231)$ & $1.089(0.923-1.285)$ & $1.086(0.921-1.282)$ & $1.052(0.851-1.300)$ \\
\hline & Informal social participation & & & & \\
\hline & No & $1.604^{* * *}(1.387-1.855)$ & $1.241^{* *}(1.063-1.449)$ & $1.244^{* *}(1.064-1.454)$ & $1.241 *(1.016-1.516)$ \\
\hline & Formal social participation & & & & \\
\hline & No & $1.678^{* * *}(1.275-2.208)$ & $1.336^{* *}(1.010-1.769)$ & $1.342^{* *}(1.012-1.778)$ & $1.424^{*}(1.007-2.013)$ \\
\hline & Social support (emotional) & & & & \\
\hline & No & $0.767(0.477-1.234)$ & $0.668(0.411-1.084)$ & $0.664(0.409-1.078)$ & $0.556(0.295-1.047)$ \\
\hline & Social support (instrumental) & & & & \\
\hline & No & $1.013(0.448-2.288)$ & $1.185(0.519-2.706)$ & $1.178(0.516-2.694)$ & $2.077(0.680-6.344)$ \\
\hline
\end{tabular}

Results are from proportional odds models. Results are displayed as ORs of change in sleep duration (taking 7-9 hours as reference) per unit increase in the original scale of generalized trust, visits and interaction with friends, participation of organized social activities, emotional social support, or instrumental social support

a Adjusted for gender, age, education, marital status, current residential area, household annual income, living alone, and pension status

b Adjusted for gender, age, education, marital status, current residential area, household annual income, living alone, pension status, smoking, alcohol drinking, and physical activity

c Adjusted for gender, age, education, marital status, current residential area, household annual income, living alone, pension status, smoking, alcohol drinking, physical activity, sleep quality, BMI, depression, $A D L$, cognitive function, $N C D$, and comorbidity

${ }^{*} p<0.05 ;{ }^{* *} p<0.01 ;{ }^{* * *} p<0.001$

Women in China, especially rural older women, also face a greater burden of discrimination and social inequality [58] that might have contributed to the insufficient sleep in response to emotional fluctuation. Therefore, those policymakers of the sleep intervention measure for the rural older females need to pay more attention to their psychological factors and emotional needs, and give them more emotional social support. A study conducted in a Japanese town demonstrated that insufficient sleep was associated with all dimensions of neighborhood social capital in men and not in women [8], which was inconsistent with the results of this study. This may be due to the different social capital types and measurements. The study measured Chinese old adults' social capital in generalized trust, social participation and social support, but it did not include the detailed neighborhood social capital.

Besides the significant effect of generalized trust and emotional social support, the results indicated the inverse association between having social participation and long sleep, which was also found among rural old women. Social participation could provide a sense of belonging and enable the old adults to better integrate into society through shared time and engagement in social activities with friends and members of community group, reduce the sense of solitude, buffer stress and make the old adults more positive in life, which promotes their sleep at night in turn [59]. Social participation could also promote sleep through physical status improvement (i.e. delay functional decline and preserved cognitive functions) and promotion of healthy behaviours [59]. In China, most men and women have different gender patterns of access to social capital, which may cause different effects of social capital on health. Chinese men are more engaged in their career, colleagues and friends, and it is more conducive for men to socialize in formal occasions and accumulate corresponding social capital. Given the traditional culture and social responsibility in China, rural women have less social participation, especially formal social participation, and higher risk of social exclusion [60-62]. Without adequate social participation, older people living 
Table 3 Logistic regression analysis of the association between social capital and sleep duration by gender

\begin{tabular}{|c|c|c|c|}
\hline & & Male & Female \\
\hline \multirow[t]{10}{*}{$<7 \mathrm{~h}$} & \multicolumn{3}{|l|}{ Generalized trust } \\
\hline & Untrustworthy & $1.129(0.872-1.461)$ & $1.083(0.848-1.384)$ \\
\hline & \multicolumn{3}{|c|}{ Informal social participation } \\
\hline & No & $0.932(0.724-1.199)$ & $0.950(0.747-1.207)$ \\
\hline & \multicolumn{3}{|c|}{ Formal social participation } \\
\hline & No & $1.055(0.756-1.472)$ & $0.914(0.621-1.346)$ \\
\hline & \multicolumn{3}{|c|}{ Social support (emotional) } \\
\hline & No & $0.933(0.412-2.113)$ & $1.502 *(1.258-1.978)$ \\
\hline & \multicolumn{3}{|c|}{ Social support (instrumental) } \\
\hline & No & $3.317(0.887-12.407)$ & $2.145(0.555-8.283)$ \\
\hline \multirow[t]{3}{*}{$>9 h$} & \multicolumn{3}{|l|}{ Generalized trust } \\
\hline & Untrustworthy & $1.055(0.776-1.434)$ & $1.066(0.793-1.434)$ \\
\hline & \multicolumn{3}{|c|}{ Informal social participation } \\
\hline & No & $1.134(0.848-1.518)$ & $1.409 *(1.065-1.864)$ \\
\hline & \multicolumn{3}{|c|}{ Formal social participation } \\
\hline & No & $1.286(0.827-2.002)$ & $1.645^{*}(1.028-2.634)$ \\
\hline & \multicolumn{3}{|c|}{ Social support (emotional) } \\
\hline & No & $0.716(0.247-2.070)$ & $0.511(0.229-1.140)$ \\
\hline & \multicolumn{3}{|c|}{ Social support (instrumental) } \\
\hline & No & $2.392(0.498-11.491)$ & $1.634(0.306-8.719)$ \\
\hline
\end{tabular}

Results are displayed as ORs of change in sleep duration (taking 7-9 hours as reference) per unit increase in the original scale of generalized trust, visits and interaction with friends, participation of organized social activities, emotional social support, or instrumental social support

Adjusted for gender, age, education, marital status, current residential area, household annual income, living alone, and pension, smoking, alcohol drinking, physical activity, sleep quality, BMI, depression, ADL, cognitive function, NCD, and comorbidity

${ }^{*} p<0.05$; ${ }^{* *} p<0.01 ;{ }^{* * *} p<0.001$

in rural areas would suffer more from depression [63], which was found associated with higher risk of longer sleep duration and daytime napping in previous research $[64,65]$. Differences in family responsibilities have led to significant gender differences in sleep outcomes, such as longer self-reported sleep in women [66].Women in Chinese society, especially in rural areas, always spend more time to give family support such as unpaid care responsibilities for grand-children and spouse [67], which makes their social capital more concentrated on their family and relatives [68]. And rural women with lower socio-economic statuses occupy the lowest participation in general leisure activities [69]. With the acceleration of urbanization, rural older women might migrate to a strange new environment for supporting their children in family chores and taking care of their grandsons/ granddaughters for their children move to town or city to get better education or work opportunities [70], so they face many challenges in adapting to the new environment, such as social isolation, language barrier, loss of network and social interaction from the place of origin, and lack of resources to rebuild their social network [71-74], which leads to less social participation. Less social participation outdoor and spending more time doing family chores and taking care of their grandchildren at home, may give them more flexibility to nap or go to bed earlier [66]. Another reason could be the poor health condition, in other words, the higher dependence on ADL reduce their willingness and ability to interact with their friends and participate in organized social activities, causing longer sleep. It also needs to be noted that the potential dark side of the impact of social capital on rural older women's health. Since rural older women have less formal social participation, the formal social participation may boost their stress [75], causing harmful effects on their health.

This study has some limitations. First, the analysis was conducted based on a cross-sectional data and did not find the cause-effect relationship between social capital and sleep duration, and the mediation mechanism of social capital on sleep in different genders needs to be further explored. Second, self-reported sleep duration every day (including napping) was used as the outcome variable, which may cause a possibility of recall bias considering that people often overestimate duration, but it is still as reliable as the objective assessments [76]. Some studies suggested sleep duration and daytime napping have similar association with certain health outcomes $[77,78]$, while some other studies found their dissimilarities [79], and future studies need to distinguish the two types of sleep in the association between social capital and sleep. Third, social capital in this study was not measured comprehensively, and different types of social participation were not all captured, for example, the older adults with insomnia were not included in the analysis due to lack of data. There were only a few cases having no emotional/instrumental social support, hence the accuracy of our estimation on the association between social capital and sleep duration would be compromised. Further study could examine how to improve social capital to promote healthy sleep and the mechanism of social capital's impact on sleep in older adults from the perspective of gender differences, considering the different individual, community, society, and culture context.

\section{Conclusions}

This study examined the relationship between social capital and sleep duration and found there were gender differences in the relationship of different dimensions of social capital and sleep disturbances in Chinese rural older adults. The results indicated the protective effect of generalized trust on insufficient sleep and the 
protective effect of informal and formal social participation on long sleep in rural older adults. For different genders, women tend to report more sleep problems than men, and there are also gender differences in the impact of social capital on sleep duration, suggesting that gender differences should be considered to promote healthier behaviors with regards to optimal sleep duration, especially the improvement of emotional social support and social participation among rural older women. Compared to the dietary or physical activity behaviour, sleep behaviour may be a more easily modifiable lifestyle factor and may therefore have significant potential to improve old adults' health [80, 81]. Given the results, more targeted sleep disturbance interventions could be taken in social capital of rural older adults, and gender differences should be considered when making social capital-embedded policies and interventions to promote healthy sleep behaviours and better social environment.

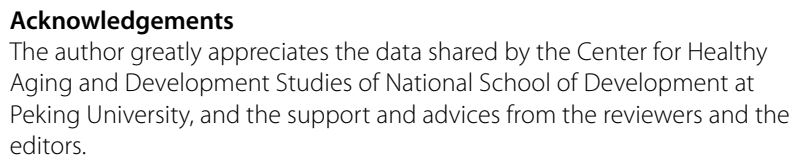

\section{Authors' contributions}

$Y L$ conceived and designed the study, analyzed the data and contributed to original draft; $\mathrm{WH}$ contributed to data collection and study design; CJ contributed to review and revision of the manuscript. All authors read and approved the final manuscript.

\section{Funding}

This study is supported by $\mathrm{PhD}$ research startup foundation of Shanxi Medical University (XD2042), PhD research startup foundation of Shanxi Province (SD2029), Program for the Philosophy and Social Sciences Key Research Base of Higher Education Institutions of Shanxi (20210136), and Philosophy and Social Science Program of Shanxi Province (2021YJ087).

\section{Availability of data and materials}

PKU Centre for Healthy Ageing and Development. 2021. "Chinese Longitudinal Healthy Longevity Survey (CLHLS)." Peking University Open Research Data. https://doi.org/10.18170/DVN/WBO7LK.

\section{Declarations}

\section{Ethics approval and consent to participate}

The data used in our research is secondary data. The data from CLHLS survey already obtained the ethical approval and informed consent and was approved by research ethics committees of Duke University and Peking University (IRB00001052-13074). All methods were carried out in accordance with relevant guidelines and regulations.

\section{Consent for publication}

Not Applicable.

\section{Competing interests}

The corresponding author states that there is no conflict of interest.

\section{Author details}

${ }^{1}$ School of Management, Shanxi Medical University, 56 Xinjian South Road, Taiyuan, Shanxi Province, China. ${ }^{2}$ School of Health Humanities, Peking University, 38 Xueyuan Road, Haidian, Beijing, China.
Received: 10 May 2021 Accepted: 17 December 2021

Published online: 05 January 2022

\section{References}

1. Vitiello MV. Sleep in normal aging. Sleep Med Clin. 2006;1(2):171-6.

2. Wu CY, Su TP, Fang CL, Chang MY. Sleep quality among communitydwelling elderly people and its demographic, mental, and physical correlates. J Chinese Med Assoc. 2012;75(2):75-80.

3. St-Onge MP, Grandner MA, Brown D, Conroy MB, Jean-Louis G, Coons $M$, et al. Sleep duration and quality: impact on lifestyle behaviors and cardiometabolic health: a scientific statement from the American Heart Association. Circulation. 2016;134:e367-86.

4. Jike M, Itani O, Watanabe N, Buysse DJ, Kaneita Y. Long sleep duration and health outcomes: a systematic review, meta-analysis and meta-regression. Sleep Med Rev. 2018;39:25-36.

5. Bliwise DL, Young TB. The parable of parabola: what the U-shaped curve can and cannot tell us about sleep. Sleep. 2007;30(12):1614-5.

6. Li J, Vitiello MV, Gooneratne NS. Sleep in normal aging. Sleep Med Clin. 2018;13(1):1-11.

7. Mohammadi MR, Hooshyari Z, Ezanloo B, Shakiba A, Mostafavi, Salmanian $M$, et al. Application of different techniques of factor analysis to develop neighborhood social capital rating scale. Soc Indic Res. 2020;150:375-91.

8. Moore S, Kawachi I. Twenty years of social capital and health research: a glossary. J Epidemiol Community Health. 2017;71(5):513-7.

9. Coleman JS. Social capital in the creation of human capital. Am J Sociol. 1988:94:95-120.

10. Putnam RD. Bowling alone: the collapse and revival of American community. New York: Simon \& Schuster; 2000.

11. Harpham T, Grant E, Thomas E. Measuring social capital within health surveys: key issues. Health Policy Plan. 2002;17(1):106e111.

12. Robbins R, Jean-Louis $G$, Gallagher RA, Hale L, Branas CC, Gooneratne N, et al. Examining social capital in relation to sleep duration, insomnia, and daytime sleepiness. Sleep Med. 2019;60:165-72.

13. Win T, Yamazaki T, Kanda K, Tajima K, Sokejima S. Neighborhood social capital and sleep duration: a population based cross-sectional study in a rural Japanese town. BMC Public Health. 2018;18(1):343.

14. Xiao H, Zhang Y, Kong D, Li S, Yang N. Social capital and sleep quality in individuals who self-isolated for 14 days during the coronavirus disease 2019 (COVID-19) outbreak in January 2020 in China. Med Sci Monit. 2020;26:e923921.

15. Yang Y, Wang S, Chen L, Luo M, Xue L, Cui D, et al. Socioeconomic status, social capital, health risk behaviors, and health-related quality of life among Chinese older adults. Health Qual Life Outcomes. 2020;18(1):291.

16. Mong JA, Cusmano DM. Sex differences in sleep: impact of biological sex and sex steroids. Philos Trans R Soc Lond Ser B Biol Sci. 2016;371(1688):20150110.

17. Norris P, Inglehart R. Gendering social capital: bowling in women's leagues? In: Gender and social capital. New York: Routledge; 2006.

18. Weidner G. Gender gap in health decline in East Europe. Nature. 1998;395(6705):835.

19. Moore G. Structural determinants of men's and women's personal networks. Am Sociol Rev. 1990;55(5):726.

20. Bassett E, Moore S. Neighbourhood disadvantage, network capital and restless sleep: is the association moderated by gender in urban-dwelling adults? Soc Sci Med. 2014;108:185-93.

21. Wang Y, Li J, Fu P, Jing Z, Zhou C. Social engagement and sleep quality among older adults in Rural China: is there a sex difference? J Am Med Dir Assoc. 2020;22(10):2140-6.

22. Tobiasz-Adamczyk B, Zawisza K. Urban-rural differences in social capital in relation to self-rated health and subjective well-being in older residents of six regions in Poland. Ann Agric Environ Med. 2017;24(2):162-70.

23. Lin X, Lu R, Guo L, Liu B. Social capital and mental health in Rural and Urban China: a composite hypothesis approach. Int J Environ Res Public Health. 2019;16(4):665.

24. Guanxi LN. A conceptual analysis. In: So AY, Lin N, Poston D, editors. The Chinese triangle of mainland China, Taiwan, and Hong Kong: Comparative institutional analysis. Westport: Greenwood Publishing Group; 2001 p. 153-66. 
25. Luo Y. Guanxi: principles, philosophies, and implications. Hum Syst Manag. 1997;16(1):43-51.

26. Hsiung B. Guanxi: personal connections in Chinese society. J Bioecon. 2013;15:17-40.

27. Mortenson ST. Interpersonal trust and social skill in seeking social support among Chinese and Americans. Commun Res. 2009;36(1):32-53.

28. Bian Y. Bringing strong ties back in: indirect ties, network bridges, and job searches in China. Am Sociol Rev. 1997;62(3):366-85.

29. Shen Y, Yeatts DE, Cai T, Yang PQ, Cready CM. Social capital and selfrated health among middleaged and older adults in China: a multilevel analysis. Res Aging. 2014;36(4):497-521.

30. He Q, Cui Y, Liang L, Zhong Q, Li J, Li Y, et al. Social participation, willingness and quality of life: a population-based study among older adults in rural areas of China. Geriatr Gerontol Int. 2017:17:1593-602.

31. Guo M, Aranda MP, Silverstein M. The impact of out-migration on the intergenerational support and psychological wellbeing of older adults in rural China. Ageing Soc. 2009;29(7):1085-104.

32. Liang $\mathrm{H}$, Yue Z, Liu E, Xiang N. How does social capital affect individual health among the elderly in rural China?-Mediating effect analysis of physical exercise and positive attitude. PLoS One. 2020;15(7):e0231318.

33. Yang Y, Meng Y. Is China moving toward healthy aging? A tracking study based on 5 phases of CLHLS data. Int J Environ Res Public Health. 2020;17(12):4343

34. Kripke DF, Garfinkel L, Wingard DL, Klauber MR, Marler MR. Mortality associated with sleep duration and insomnia. Arch Gen Psychiatry. 2002:59(2):131-6

35. Xue X, Reed WR, Menclova A. Social capital and health: a meta-analysis. J Health Econ. 2020;72:102317.

36. Giordano GN, Lindstrom M. The impact of changes in different aspects of social capital and material conditions on self-rated health over time: a longitudinal cohort study. Soc Sci Med. 2010;70(5):700-10.

37. Moore S, Carpiano MR. Measures of personal social capital over time: A path analysis assessing longitudinal associations among cognitive, structural, and network elements of social capital in women and men separately. Soc Sci Med. 2020;257:112172.

38. Herberholz C, Phuntsho S. Social capital, outpatient care utilization and choice between different levels of health facilities in rural and urban areas of Bhutan. Soc Sci Med. 2018;211:102-13.

39. Zettel-Watson L, Britton M. The impact of obesity on the social participation of older adults. J Gen Psychol. 2008;135(4):409-24.

40. Hou C, Lin Y, Zimmer Z, Tse LA, Fang X. Association of sleep duration with risk of all-cause mortality and poor quality of dying in oldestold people: a community-based longitudinal study. BMC Geriatr. 2020;20(1):357.

41. Chen X, Wang SB, Li XL, Huang ZH, Tan WY, Lin HC, et al. Relationship between sleep duration and sociodemographic characteristics, mental health and chronic diseases in individuals aged from 18 to 85 years old in Guangdong province in China: a population-based cross-sectional study. BMC Psychiatry. 2020;20(1):455.

42. Li W, Wu M, Yuan F, Zhang H. Sugary beverage consumption mediates the relationship between late chronotype, sleep duration, and weight increase among undergraduates: a cross-sectional study. Environ Health Prev Med. 2018;23(1):63.

43. Zhang $Y$, Xiong $Y, Y u Q$, Shen $S$, Chen $L$, Lei $X$. The activity of daily living (ADL) subgroups and health impairment among Chinese elderly: a latent profile analysis. BMC Geriatr. 2021;21(1):30

44. Cheng HG, Chen S, McBride O, Phillips MR. Prospective relationship of depressive symptoms, drinking, and tobacco smoking among middleaged and elderly community-dwelling adults: results from the China health and retirement longitudinal study (CHARLS). J Affect Disord. 2016;195:136-43

45. Shen K, Zhang B, Feng Q. Association between tea consumption and depressive symptom among Chinese older adults. BMC Geriatr. 2019;19(1):246.

46. Winship C, Radbill L. Sampling weights and regression analysis. Sociol Methods Res. 1994;23:230-57.

47. Hendrikx J. The impact of weights on standard errors. Presented at the annual meeting of the Association for Survey Computing, April 17, Imperial College, London, 2002. Available at http://www.asc.org.uk/ Events/Apr02/Full/Hendrickx.doc (Accessed 8 Aug 2006).
48. Hamilton NA, Nelson CA, Stevens N, Kitzman H. Sleep and psychological well-being. Soc Indic Res. 2007;82(1):147-63.

49. Lu H, Tong P, Zhu R. Longitudinal evidence on social trust and happiness in China: causal effects and mechanisms. J Happiness Stud. 2020:21:1841-58

50. Jarrin DC, Chen IY, Ivers H, Morin CM. The role of vulnerability in stressrelated insomnia, social support and coping styles on incidence and persistence of insomnia. J Sleep Res. 2014;23(6):681-8.

51. Prati B, Pietrantoni L. The relation of perceived and received social support to mental health among first responders: a meta-analytic review. J Community Psychol. 2010;38:403-17.

52. Yeh SC, Liu YY. Influence of social support on cognitive function in the elderly. BMC Health Serv Res. 2003:3(1):9.

53. Berkman LF, Glass T, Brissette I, Seeman TE. From social integration to health: Durkheim in the new millennium. Soc Sci Med. 2000;51(6):843-57.

54. Kent de Grey RG, Uchino BN, Trettevik R, Cronan S, Hogan JN. Social support and sleep: a meta-analysis. Health Psychol. 2018;37:787-98.

55. Xiao H, Zhang Y, Kong D, Li S, Yang N. The effects of social support on sleep quality of medical staff treating patients with coronavirus disease 2019 (COVID-19) in January and February 2020 in China. Med Sci Monit. 2020;26:e923549

56. Armitage R, Hoffmann RF. Sleep EEG, depression and gender. Sleep Med Rev. 2001;5(3):237-46.

57. Kim HJ, Oh SY, Joo JH, Choi DW, Park EC. The relationship between sleep duration and perceived stress: findings from the 2017 Community Health Survey in Korea. Int J Environ Res Public Health. 2019;16(17):3208.

58. Zhao SZ, Wang MP, Viswanath K, Lai A, Fong DYT, Lin CC, et al. Short sleep duration and insomnia symptoms were associated with lower happiness levels in Chinese adults in Hong Kong. Int J Environ Res Public Health. 2019;16(12):2079

59. Chen JH, Lauderdale DS, Waite LJ. Social participation and older adults' sleep. Soc Sci Med. 2016;149:164-73.

60. Wu H. Hollow lives: women left behind in Rural China hollow lives: women left behind in Rural China. J Agrar Chang. 2015;16(1):50-69.

61. Wang Z, Dai W. Women's participation in Rural China's self-governance: institutional, socioeconomic, and cultural factors in a Jiangsu County. Governance. 2013;26:91-118.

62. Yang Y, Yeung WJ, Feng Q. Social exclusion and cognitive impairment-A triple jeopardy for Chinese rural elderly women. Health Place. 2018;53:1 17-27.

63. Guo Q, Bai X, Feng N. Social participation and depressive symptoms among Chinese older adults: a study on rural-urban differences. J Affect Disord. 2018:239:124-30.

64. Zaidel C, Musich S, Karl J, Kraemer S, Yeh CS. Psychosocial factors associated with sleep quality and duration among older adults with chronic pain. Popul Health Manag. 2021;24(1):101-9.

65. Liu Y, Peng T, Zhang S, Tang K. The relationship between depression, daytime napping, daytime dysfunction, and snoring in 0.5 million Chinese populations: exploring the effects of socio-economic status and age. BMC Public Health. 2018;18(1):759.

66. Burgard SA, Ailshire JA. Gender and time for sleep among US adults. Am Sociol Rev. 2013;78(1):51-69.

67. Cook S, Dong XY. Harsh choices: Chinese women's paid work and unpaid care responsibilities under economic reform. Dev Chang. 2011:42(4):947-65.

68. Li S, Ren W. "Family-bound" or "pulled by work"? - a study of Chinese Women's social participation and the factors influencing it. Soc Sci China. 2020:41(1):133-58.

69. Chen N, Tsai C. Rural-urban divide and the social stratification in leisure participation in China: application of multiple hierarchy stratification perspective. Appl Res Qual Life. 2020;15(5):1535-48.

70. Giles J, Mu R. Elder parent health and the migration decision of adult children: evidence from rural China. Demography. 2006;44(2):265-88.

71. Li Q, Zhou X, Ma S, Jiang M, Li L. The effect of migration on social capital and depression among older adults in China. Soc Psychiatry Psychiatr Epidemiol. 2017;52(12):1513-22.

72. Cheong PH. Communication context, social cohesion and social capital building among hispanic immigrant families. Community Work Fam. 2006:9(3):367-87.

73. Chen X, Stanton B, Kaljee LM, Fang X, Xiong Q, Lin D, et al. Social stigma, social capital reconstruction and rural migrants in urban China: a population health perspective. Hum Organ. 2011;70(1):22-32. 
74. Cheng Y, Rosenberg M, Winterton R, Blackberry I, Gao S. Mobilities of older Chinese rural-urban migrants: a case study in Beijing. Int J Environ Res Public Health. 2019;16(3):488.

75. Pinillos-Franco S, Kawachi I. The relationship between social capital and self-rated health: a gendered analysis of 17 European countries. Soc Sci Med. 2018;219:30-5.

76. Lauderdale DS, Knutson KL, Yan LL, Liu K, Rathouz PJ. Self-reported and measured sleep duration: how similar are they? Epidemiology. 2008:19:838-45.

77. Yang L, Xu Z, He M, Yang H, Li X, Min X, et al. Sleep duration and midday napping with 5-year incidence and reversion of metabolic syndrome in middle-aged and older Chinese. Sleep. 2016;39(11):1911-8.

78. Lin JF, Li FD, Chen XG, He F, Zhai YJ, Pan XQ, et al. Association of postlunch napping duration and night-time sleep duration with cognitive impairment in Chinese elderly: a cross-sectional study. BMJ Open. 2018:8(12):e023188.

79. Ye Y, Zhang L, Yan W, Wang A, Wang W, Gao Z, et al. Self-reported sleep duration and daytime napping are associated with renal hyperfiltration and microalbuminuria in an apparently healthy Chinese population. PLoS One. 2019:14(8):e0214776.

80. Peltzer K. Differences in sleep duration among four different population groups of older adults in South Africa. Int J Environ Res Public Health. 2017;14(5):502.

81. Egan KJ, Knutson KL, Pereira AC, von Schantz M. The role of race and ethnicity in sleep, circadian rhythms and cardiovascular health. Sleep Med Rev. 2017;33:70-8.

\section{Publisher's Note}

Springer Nature remains neutral with regard to jurisdictional claims in published maps and institutional affiliations.

- fast, convenient online submission

- thorough peer review by experienced researchers in your field

- rapid publication on acceptance

- support for research data, including large and complex data types

- gold Open Access which fosters wider collaboration and increased citations

- maximum visibility for your research: over $100 \mathrm{M}$ website views per year

At $\mathrm{BMC}$, research is always in progress.

Learn more biomedcentral.com/submissions 